\title{
Low-dose anti-thymocyte globulin plus low-dose posttransplant cyclophosphamide as graft-versus-host disease prophylaxis in haploidentical peripheral blood stem cell transplantation combined with unrelated cord blood for patients with hematologic malignancies: a prospective, phase II study
}

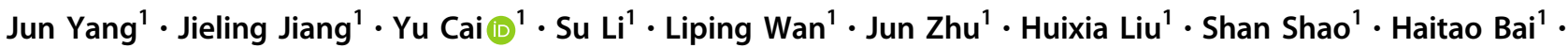 \\ Chun Wang ${ }^{1} \cdot$ Xianmin Song ${ }^{1}$
}

Received: 9 July 2018 / Revised: 12 September 2018 / Accepted: 9 October 2018 / Published online: 16 November 2018

(c) The Author(s) 2018. This article is published with open access

\begin{abstract}
Nowadays, the most wildly used regimens for graft-versus-host disease (GvHD) prophylaxis in haplo-hematopoietic stem cell transplantation (Haplo-HSCT) are based on in vivo T-cell depletion (TCD) with anti-thymocyte globulin (ATG) or posttransplant cyclophosphamide (PTCy). To improve the efficiency of GvHD prophylaxis in haploidentical peripheral blood stem cell transplantation combined with unrelated cord blood (Haplo-PBSCT-Cord), a novel regimen, which is composed of low dose of ATG $(5 \mathrm{mg} / \mathrm{kg})$ and low-dose PTCy $(50 \mathrm{mg} / \mathrm{kg})$ for GvHD prophylaxis, was evaluated in a prospective phase II clinical trial (Clinicaltrials.org NCT03395860). Thirty-two patients diagnosed with hematological malignancies were enrolled in this trial. All patients received myeloablative conditioning regimens except for three patients. The cumulative incidences (CIs) of grades II-IV and III-IV acute GvHD were 19.4\% (95\% CI, 5.5-33.3\%) and 6.9\% (95\% CI, $0-16.3 \%$ ) by day 100 , respectively. The 1-year probability of relapse, disease free survival (DFS) and overall survival (OS) was $25.1 \%$ (95\% CI, 7.3-42.9\%), 59\% (95\% CI, 33.3-84.7\%) and 78.4\% (95\% CI, 63-93.8\%), respectively. The CIs of CMV and EBV reactivation by day 180 were $37.5 \%$ (95\% CI, 19.8-55.2\%) and 40.6\% (95\% CI, 22.6-58.6\%), respectively. The results suggested that low-dose ATG with low-dose PTCy as GvHD prophylaxis in Haplo-PBSCT-Cord had promising activity.
\end{abstract}

\section{Introduction}

Acute graft-versus-host disease (aGvHD) is the most important obstacle of haploidentical hematopoietic stem cell transplantation (Haplo-HSCT) for treatment of patients with hematologic malignancies. In the last two decades, the results of Haplo-HSCT have been conspicuously improved due to effective prophylaxis strategies for aGvHD, such as

These authors contributed equally: Jun Yang, Jieling Jiang

Xianmin Song

shongxm@sjtu.edu.cn

1 Department of Hematology, Shanghai General Hospital (affiliated to Shanghai Jiao Tong University), No. 100 Haining Road, 200080 Shanghai, China in vivo T-cell depletion (TCD) with anti-thymocyte globulin (ATG) or posttransplant cyclophosphamide (PTCy) [1, 2].

The regimens for prophylaxis of GvHD based on rabbit anti-human thymocyte immunoglobin (ATG $10 \mathrm{mg} / \mathrm{kg}$, Thymoglobin ${ }^{\circledR}$, Genzyme Polyclonals S.A.S) effectively prevented the occurrence of grade II-IV aGvHD with incidences of $33.4-46 \%$, grade III-IV aGvHD 12-14.9\%, but the reactivation incidences of cytomegalovirus (CMV) and EB virus (EBV) were higher due to a slower immune reconstitution [2-4]. The 100-day CIs of CMV and EBV viremia were $61-64 \%[2,5]$ and over $50 \%$ [5, 6], respectively. Although ATG-based regimens have achieved excellent results, the incidences of aGvHD and the posttransplant virus reactivation are still higher, affecting the long-term survival of the patients.

The regimen of PTCy for prevention of GvHD was developed in 1999 by St. Johns Hopkin's group in Baltimore [1] and had outstanding results with the CIs of $34 \%$ 
grades II-IV and $6 \%$ grades III-IV aGvHD by day 200 in Haplo-bone marrow transplantation (Haplo-BMT) [7], respectively. Compared with standard PTCy regimen (two doses of PTCy; day $+3,+4)$, one dose of PTCy $($ day +3$)$ had similar effects in preventing aGvHD, but was less effective for chronic GvHD (cGvHD), especially serious cGvHD [7]. The incidences of viral and fungal infection in Haplo-HSCT with PTCy for GvHD prophylaxis were much lower than ATG-based regimens. Ruggeri et al. [8] retrospectively analyzed the effects of different stem cell source (BM vs peripheral blood stem cell (PBSC)) on transplant results in Haplo-HSCT with PTCy. The results showed that BM graft was associated with a lower incidence of grades II-IV and grades III-IV acute GVHD (21 vs 38\%, $P \leq .01$; and 4 vs 14\%, $P<.01$, respectively), which was further confirmed by Bashey et al.'s study [9]. These data indicated that PTCy regimen did not have the same effects for GvHD prophylaxis with PBSC graft as compared with BM graft in Haplo-HSCT.

A novel regimen, which is composed of a low dose of ATG $(5 \mathrm{mg} / \mathrm{kg}$ ) and low-dose PTCy (one dose of PTCy, 50 $\mathrm{mg} / \mathrm{kg}$ ) for GvHD prophylaxis in Haploidentical peripheral blood stem cell transplantation combined with unrelated cord blood (Haplo-PBSCT-Cord) for patients with hematologic malignancies, was designed to decrease the risk of aGvHD and lower the incidence of virus reactivation. A prospective, phase II clinical trial (Clinicaltrials.org NCT03395860) was performed to evaluate the efficacy with low-dose ATG followed by low-dose PTCy as GvHD prophylaxis. The results suggested that the novel regimen had excellent outcomes for aGvHD prophylaxis in HaploPBSCT-Cord.

\section{Patients and methods}

\section{Patients' eligibility}

Total 32 eligible patients were enrolled into the clinical trial with ages from 20- to 62-year-old with hematologic malignancies including acute myeloid leukemia (AML), acute lymphoblastic leukemia (ALL), high-risk myelodysplasia (MDS), chronic myelomonocytic leukemia (CMML) from June 2017 to January 2018 in our center. ECOG performance status was $\leq 2$ in all patients. All patients had adequate baseline laboratory values for eligibility. This study had ethical approval from the local ethical committees and conducted in accordance with the Declaration of Helsinki. All patient data originate from clinical trials with mandatory written informed consent.

Patients were ineligible if they had a central nervous system (CNS) disease, active uncontrolled bacterial, viral or fungal infections, or severe organ dysfunction, including a left ventricular ejection fraction $<40 \%$ and alanine transaminase (ALT)/aspartate transaminase $(\mathrm{AST})>2.5 \times$ the upper normal limit. The comorbidity index of each patient was calculated using the hematopoietic cell transplantationcomorbidity index system.

\section{Study design and treatment}

\section{Donors and stem cell sources}

Family members selected as donors were typed on the HLA-A, -B, -C, -DRB1 and -DQB1 locus at high-resolution level. Haplotype was defined as recipient-donor number of HLA mismatches $>3$ [10]. Unrelated cord blood (UCB) was co-infused with PBSC graft as the third-party cells at 4 $\mathrm{h}$ before the stem cell graft infusion. UCB was preferentially selected based on HLA 4-5/6 matched to total cell number. The PBSC grafts for all patients were mobilized with G-CSF. The target value for $\mathrm{CD} 34^{+}$cells in mobilized PBSC graft is a minimum of $10 \times 10^{6} / \mathrm{kg}$ of recipient weight.

\section{Conditioning regimens}

Reduced-intensity conditioning (RIC) was given to the patients above 55 years old ( $\geq 55$ years), while myeloablative conditioning regimens (MACs) were designed for patients below 55 years old ( $<55$ years). The conditioning regimens for myeloid malignancies including AML, MDS and CMML were based on intravenous busulfan $3.2 \mathrm{mg} / \mathrm{kg} /$ day for 3 days in MACs (2 days in RIC), fludarabine $30 \mathrm{mg} /$ $\mathrm{m}^{2} /$ day and cytarabine (Ara-C) $1-2 \mathrm{~g} / \mathrm{m}^{2} /$ day for 5 days. All the patients with ALL received MAC regimen, which consisted of total body irradiation (10 Gy in five fractions), cyclophosphamide $(60 \mathrm{mg} / \mathrm{kg} /$ day for 2 days) and etoposide (15 mg/kg/day for 2 days) (Fig. 1)

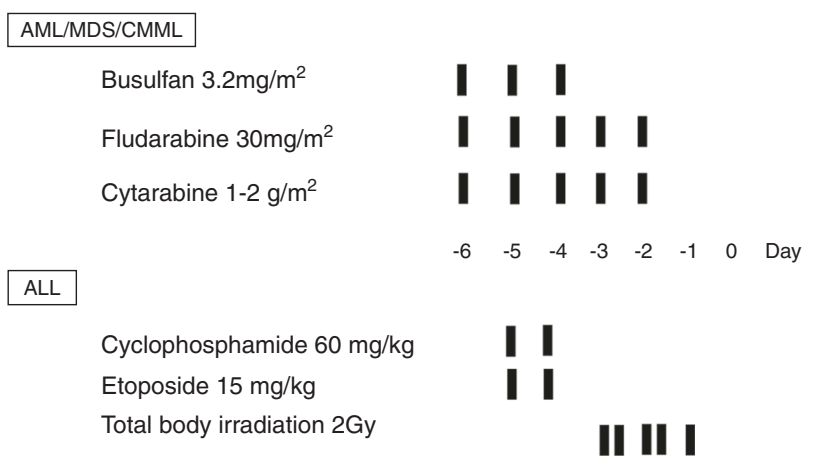

Fig. 1 The schema of myeloablative conditioning (MAC) regimens for myeloid malignancies and acute lymphoblastic leukemia 


\section{GvHD prophylaxis}

The GvHD prophylaxis consisted of ATG $2.5 \mathrm{mg} / \mathrm{kg}$ administered on day -2 to -1 and cyclophosphamide (Cy) $50 \mathrm{mg} / \mathrm{kg}$ on day +3 , cyclosporine A (CsA) and mycophenolate mofetil (MMF) initiating on day +4 . CsA was prescribed at $2 \mathrm{mg} / \mathrm{kg}$ as a continuous infusion. The CsA doses were modified to obtain nadir serum levels between 200 and $300 \mathrm{ng} / \mathrm{ml}$. MMF was administered at $15 \mathrm{mg} / \mathrm{kg}$ oral three times per day (maximum dose $3 \mathrm{~g}$ per day) until day +34 and was then stopped if no aGvHD. Mycophenolate Sodium Enteric-coated Tablets (MPA) can be used instead of MMF; one tablet MPA corresponds to one tablet MMF. CsA was tapered from day +90 to day +180 .

\section{Supportive care}

G-CSF was given to all patients since day +5 until neutrophil recovery. All patients received prophylactic levofloxacin, acyclovir from the beginning of conditioning therapy until hematological reconstitution. Prophylactic posaconzale was administered from the day of the conditioning until 1 month after transplant [11]. Quantitative real-time PCR assays for CMV DNA in serum and EBV DNA in whole blood were performed once or twice per week. Preemptive therapy with ganciclovir $(5 \mathrm{mg} / \mathrm{kg}$, twice) started if CMV DNA was more than 1000 copies $/ \mathrm{ml}$. Preemptive therapy with rituximab (a single dose $375 \mathrm{mg} / \mathrm{m}^{2}$ ) was initiated when EBV DNA increased a log or more within 1 week or above $1 \times 10^{5}$ copies/ml in high-risk patients [12] with EBV reactivation. EBV-related posttransplant lymphoproliferative disease (PTLD) was treated with reducing dose of immunosuppressive agents (RIS) and rituximab once per week for maximum of four courses [13].

\section{Engraftment and GvHD evaluation}

The engraftment endpoint was based on neutrophil engraftment with absolute neutrophil count (ANC) $\geq$ $0.5 \times 10^{9} / 1$ for 3 consecutive days after transplantation without G-CSF. Platelet engraftment was defined as the first of 7 consecutive days with platelet counts of $>20 \times 10^{9} / 1$ without platelet transfusion. Graft failure was defined as failure of neutrophil engraftment on day 28 following transplantation (primary graft failure), or loss of donor chimerism after initial engraftment with $\geq 95 \%$ recipient cells at any time, not due to relapsed disease (secondary graft failure) [14].

aGvHD was diagnosed and graded according to the modified Glucksberg grading of aGvHD [15]. cGvHD was diagnosed and graded according to the 2014 National Institutes of Health (NIH) consensus criteria: mild, moderate, or severe, respectively [16].

\section{Chimerism monitoring}

Quantitative chimerism monitoring [17] was performed by short-tandem repeat (STR)-based PCR techniques on CD3positive cell population from bone marrow and by fluorescent in situ hybridization [18] for patients with sexmismatched donors at regular intervals of every 4 weeks after transplant within first 6 months. The chimerism of cord blood was also monitored after transplantation with STRbased PCR techniques until continuous twice results without cord blood components. Mixed T-cell chimerism was defined as between 5 and $94 \%$ recipient cells and complete donor chimerism was defined as the presence of more than 95\% donor cells at all measured time points [19].

\section{Statistical analysis}

The primary endpoint was the CIs of aGvHD within 100 days after Haplo-PBSCT. The secondary endpoint was the engraftment (leukocyte and platelet engraftment, donor chimerism), NRM, cGvHD, the CIs of relapse (CIRs), OS, disease-free survival (DFS), CIs of CMV viremia and CMV-associated diseases, EBV viremia and PTLDs. Only patients with successful ANC engraftment were evaluated for aGVHD and cGVHD was evaluated only in patients with a minimum follow-up of 100 days. CIR was calculated from the date of allo-HSCT or the date of getting CR after transplantation until relapse. The response criteria for $\mathrm{CR}$ and relapse were defined according to the literature [20]. Primary refractory disease was defined as the failure of achieving $\mathrm{CR}$ after two cycles of initial induction chemotherapy or hematologic relapse within 6 months from the beginning of initial therapy. Secondary refractory disease was defined as relapse from CR and had no response to salvage chemotherapy. NRM was defined as death without evidence of disease relapse. All statistical tests were twosided and $P$ value $<0.05$ was considered significant. The statistical analyses were performed using IBM SPSS 17.0 statistical software (IBM, North Harbour, Portsmouth, UK).

\section{Results}

\section{Patient characteristics}

Thirty-two patients with hematologic malignancies were diagnosed and recruited from June 2017 to January 2018 in our center. Median age was 37 years (range, 20-62 years). At the time of transplantation, a total of 14 patients with AML/ALL reached first or subsequent complete response (CR1, $\geq \mathrm{CR} 2$ ) with conventional therapy or salvage therapy; the other 18 patients had active disease without responding 
Table 1 Patient demographics

\begin{tabular}{|c|c|}
\hline & Median (range) \\
\hline Median age & $37(20-62)$ \\
\hline \multicolumn{2}{|l|}{ Sex } \\
\hline Male & 18 \\
\hline Female & 14 \\
\hline Median interval from diagnosis to & $8(4-60)$ \\
\hline \multicolumn{2}{|l|}{ HSCT, months(range) } \\
\hline \multicolumn{2}{|l|}{ Diagnosis } \\
\hline De novo AML & 22 \\
\hline ALL & 5 \\
\hline MDS-EB II & 3 \\
\hline CMML & 2 \\
\hline \multicolumn{2}{|l|}{ Disease status at transplantation } \\
\hline CR1 & 12 \\
\hline$\geq \mathrm{CR} 2$ & 2 \\
\hline Primary refractory & 7 \\
\hline Secondary refractory & 11 \\
\hline HCT-CI Median (range) & $0(0-1)$ \\
\hline \multicolumn{2}{|l|}{ Conditioning regimens } \\
\hline MAC & 29 \\
\hline RIC & 3 \\
\hline \multicolumn{2}{|l|}{ Donor relationship with patients } \\
\hline Sibling & 7 \\
\hline Parents & 8 \\
\hline \multicolumn{2}{|l|}{ Mother/father } \\
\hline Offspring & 15 \\
\hline Cousin & 2 \\
\hline
\end{tabular}

$A M L$ acute myelocytic leukemia, $M D S-E B$ II myelodysplastic syndrome with excess blasts, type II, $C M M L$ chronic myelomonocytic leukemia, $A L L$ acute lymphoblastic leukemia, $C R$ complete remission, $M A C$ myeloablative conditioning regimen, RIC reduced-intensity conditioning, HCT-CI Hematopoietic Cell TransplantationComorbidity Index [34]

to salvage therapy including three ALL, three MDS-EB II, two CMML and ten AML patients. The overall characteristics of the patients and donors are summarized in Table 1.

\section{Engraftment}

All patients received G-CSF mobilized PBSC with MNCs $15.5(7.5-28.3) \times 10^{8} / \mathrm{kg}$ and $\mathrm{CD}^{+} 4^{+}$cells $13.39 \quad(2.4$ $-31.7) \times 10^{6} / \mathrm{kg}$. The median nuclear cell number and CD34 ${ }^{+}$ cell number of unrelated third-party cord blood were 2.1 $(1.4-4.14) \times 10^{7} / \mathrm{kg}$ and $5.6(1.52-11.2) \times 10^{4} / \mathrm{kg}$, respectively. The median time for neutrophil engraftment was 12 days (range 9-20) for patients with primary engraftment; whereas the median time for platelet engraftment was observed in 16 days (range 12-25). The results of chimerism monitoring showed that all of these patients were fully donor chimerism when assessed between days 14 and

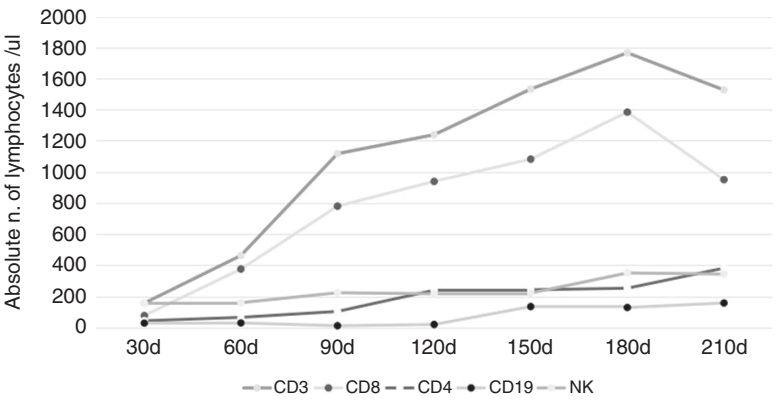

Fig. 2 Immune reconstitution after transplantation (data were shown as median cell counts/ $\mu \mathrm{l})$

28 after transplantation. Primary graft failure occurred in one patient $(3.1 \%)$ with CMML who received lower $\mathrm{CD} 34^{+}$ cell number of $2.4 \times 10^{6} / \mathrm{kg}$. One patient with AML experienced secondary graft failure after CMV pneumonia at day 90. There was no chimerism of cord blood cells in all patients on day 14 after transplantation.

\section{Immune reconstitution}

The median lymphocyte counts, stratified by $\mathrm{CD}^{+}, \mathrm{CD}^{+}$, $\mathrm{CD}^{+}, \mathrm{CD} 9^{+}$and $\mathrm{CD} 56 / \mathrm{CD}_{16}{ }^{+}$, is depicted in Fig. 2. Twenty-two patients were included in immune reconstitution studies and 15 cases were analyzed at each endpoint. On day +100 and +120 , median $\mathrm{CD}^{+}, \mathrm{CD}^{+} \mathrm{CD}^{+}$, $\mathrm{CD}^{+}{ }^{+}$and $\mathrm{CD} 56 / \mathrm{CD} 16^{+}$counts were 1117 (442-2136) and 1239 (494-2117), 104 (31-159) and 240 (201-487), $780(310-1914)$ and $939(366-1614), 12(6-42)$ and 20 (10-145), $224(78-1961)$ and $217(64-1680) / \mu 1$, respectively. Since 120 days after transplantation, $\mathrm{CD} 4^{+}$cell counts were all above $200 / \mu \mathrm{l}$ and reached nearly $400 / \mu \mathrm{l}$ on +210 days.

\section{GvHD and infectious complications}

The CI of grades II-IV aGvHD was $19.4 \%$ (95\% CI, 5.5$33.3 \%$ ) (Fig. 3a) and grades III-IV aGvHD was 6.9\% (95\% CI 0-16.3\%) (Fig. 3b) within 100 days after transplantation. The frequencies of aGVHD at day +100 and +180 were same due to no patient suffering from late onset aGVHD. The grade II aGvHD involvement of isolated skin occurred in two patients, while skin and gut in two patients. The grade III aGvHD involvement of gut and skin occurred in one patient, while skin and liver in another patient. No patient developed grade IV aGvHD. All six cases with aGvHD received systemic corticosteroids (methylprednisolone (MP) with $2 \mathrm{mg} / \mathrm{kg} / \mathrm{d}$ ). Two of them required secondary treatment with anti-CD25 mAbs (basiliximab, Novartis Pharma AG, Basel, Switzerland) because of refractory to primary therapy and both got complete remission. The CIs of moderate-to-severe cGvHD within 6 months were $18.8 \%$ 


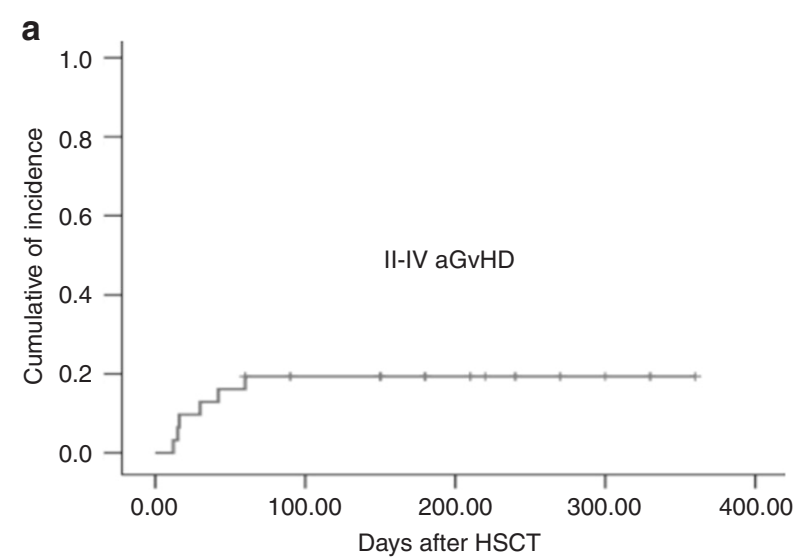

b

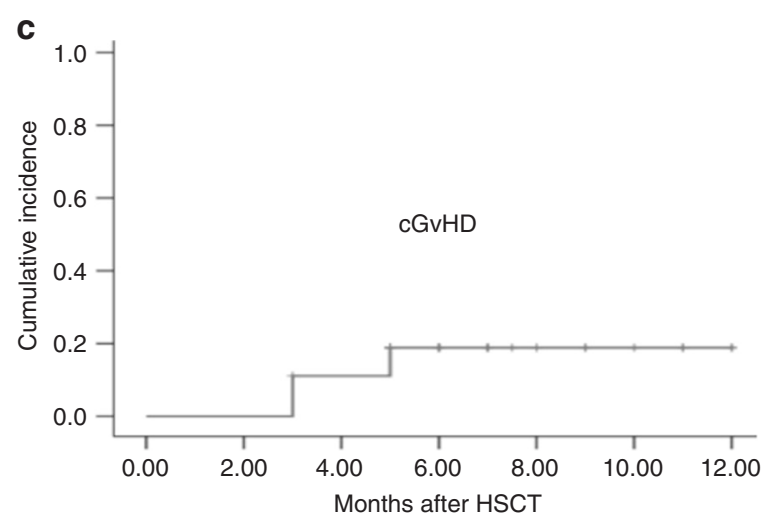

Fig. 3 The cumulative incidences (CIs) of graft-versus-host disease (GvHD). a The CIs of grades II-IV aGvHD. b The CIs of grades III-IV aGvHD. c The 1-year CIs of cGvHD

$(5 / 27$ cases, four with moderate cGVHD and one with severe cGVHD (95\% CI, 3.933.7\%)) (Fig. 3c). No patient died from acute and chronic GvHD. The CIs of CMV and EBV reactivation by day +180 were $37.5 \%$ (12 cases) $(95 \%$ CI, $19.8-55.2 \%)$ and $40.6 \%$ (13 cases) (95\% CI, 22.6 $-58.6 \%)$ respectively. Six patients suffered from pneumonia (bacterial pneumonia in one patient, aspergillus pneumonia in three patients, CMV pneumonia in one patient and pneumocystis carinii pneumonia in one patient). One patient was diagnosed as PTLD at 3 months after transplantation and died from aspergillus pneumonia (Table 2).

\section{NRM, relapse and survival}

Three patients died of nonrelapse causes (NRM 3/32, 9.4 $\%)$. One patient with CMML in non-remission (NR) experienced primary graft failure due to a low number of $\mathrm{CD} 34^{+}$cells in graft from his 60 -year-old donor and finally died from CNS hemorrhage at 1.5 months after transplantation. One patient with AML experienced secondary graft failure after CMV pneumonia and soon died. Another patient died from aspergillus pneumonia at 6 months after transplantation (Table 3). There was no death due to acute or chronic GvHD.
Table 2 Infectious complications after haplo-PBSCT-Cord

\begin{tabular}{ll}
\hline & $N(\%)$ \\
\hline CMV viremia & $12(37.5 \%)$ \\
CMV disease & $1(3.1 \%)$ \\
EB infection viremia & $13(40.6 \%)$ \\
PTLD EB related & $1(3.4 \%)$ \\
Hemorrhagic cystitis BK virus-related & $5(15.6 \%)$ \\
Pneumonia & \\
$\quad$ Virus & $1(3.1 \%)$ \\
$\quad$ Fungal & $3(9.4 \%)$ \\
$\quad$ Bacteria & $1(3.1 \%)$ \\
Pneumocystis carinii pneumonia & $1(3.1 \%)$ \\
\hline
\end{tabular}

$\overline{C M V}$ cytomegalovirus, PTLD posttransplant lymphoproliferative disorder

Seventeen out of 18 patients with active disease achieved CR after transplantation. With a median follow-up of 7 months (range, 2-12 months), six cases relapsed. All the six patients were in disease active status with blasts from 6 to $18 \%$ at the time of transplantation. Four of five patients with normal cytogenetics had DNMT3-A mutation (one case), NRAS mutation (two cases), and MLL-AF9 
rearrangement (one case), respectively. One patient with ALL had cytogenetic abnormalities with 46xy, der(3), der (9). The median time of relapse was 4.5 (3-10) months. One patient achieved the second CR (CR2) and was still alive after chemotherapy followed by donor lymphocyte infusion (DLI) for 5 months. Two patients were still in treatment. All other three patients died from relapse without treatment (Table 3). The 1-year probability of relapse was $25.1 \%$ (95\% CI, 7.3-42.9\%) for all patients (Fig. 4a). The 1-year probabilities of DFS and OS were $59 \%$ (95\% CI, $33.3-84.7 \%)$ and $78.4 \%(95 \% \mathrm{CI}, 63-93.8 \%)$, respectively (Fig. 4b).

\section{Discussion}

Data from our prospective study showed that the CIs of grades II-IV aGvHD and grades III-IV aGvHD within days 100 posttransplantation were $19.4 \%$ (95\% CI, 5.5-33.3\%) and $6.9 \%$ (95\% CI 0-16.3\%) in Haplo-PBSCT-Cord with low-dose ATG plus low-dose PTCy regimen for GvHD prophylaxis respectively, which were much lower than the results using PTCy regimen or ATG-based regimens [2, 7]. The incidence of cGvHD was $18.8 \%$ (95\% CI, 3.9-33.7\%). No patient died due to aGvHD. The results suggested that

Table 3 Causes of death

\begin{tabular}{lc}
\hline Causes of death & No. \\
\hline Relapse & 3 \\
GvHD & 0 \\
Lung infection & 2 \\
CNS hemorrhage & 1 \\
\hline
\end{tabular}

GvHD graft-versus-host disease CNS central nervous system

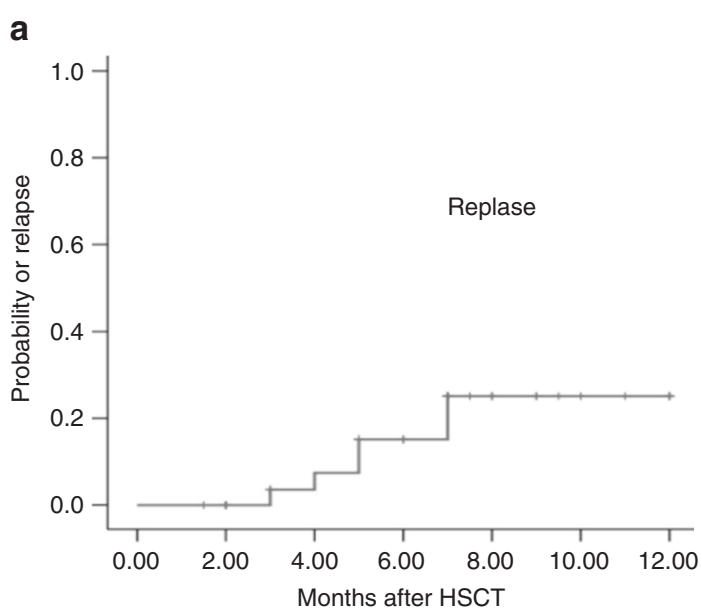

Fig. 4 Clinical outcomes after Haplo-PBSCT-Cord. a The 1-year probability of relapse. b The 1-year probability of disease-free survival (DFS) and overall survival (OS)

low-dose ATG plus low-dose PTCy could effectively prevent aGvHD in patients who undergo Haplo-PBSCT-Cord as good as standard PTCy regimen for Haplo-BMT. PBSC graft was the independent risk factor of aGvHD in HaploHSCT with PTCy regimen [8]. We speculated that more T lymphocytes and different T-cell dynamics in PBSC graft post-transfusion as compared with $\mathrm{BM}$ graft might be the major factor for unsatisfied prevention of aGvHD with standard PTCy regimen for Haplo-PBSCT. T lymphocytes in G-CSF-primed PBSC graft might enter into cell cycle at an earlier time than that in BM graft after infusion, so that the first dose of $\mathrm{Cy}$ on day +3 in standard PTCy regimen might be late for early active $\mathrm{T}$ lymphocytes, because $\mathrm{Cy}$ could induce immune tolerance only when it was given precisely between 48 and $72 \mathrm{~h}$, not 24 or $96 \mathrm{~h}$ after transplantation [21]. But it needs to be further studied. Pretransfusion low-dose ATG could deplete early active T lymphocytes to prevent the occurrence of aGvHD in combination with PTCy on day +3 with synergistic effects due to their different mechanisms of ATG and Cy on $\mathrm{T}$ lymphocytes.

The engraftment rate was analyzed as the second clinical endpoint. All patients but one were successfully engrafted after transplantation. Thirty-one patients achieved full donor chimerisms between days 14 and 28 after transplantation. But one patient experienced secondary graft failure after CMV pneumonia on +90 days. The engraftment rate in our study was acceptable. In an earlier study about PTCy regimen for GvHD prophylaxis with NMAC regimen, the engraftment failure rate was $13 \%$ and it was improved by adding total dose of Cy $29 \mathrm{mg} / \mathrm{kg}$ on days -6 and -5 pretransfusion, which suggested that increasing immunosuppressive intensity facilitated engraftment. Wang et al. [22] reported a randomized clinical trial comparing two different doses of ATG (6 and $10 \mathrm{mg} / \mathrm{kg}$ ) as GvHD prophylaxis for

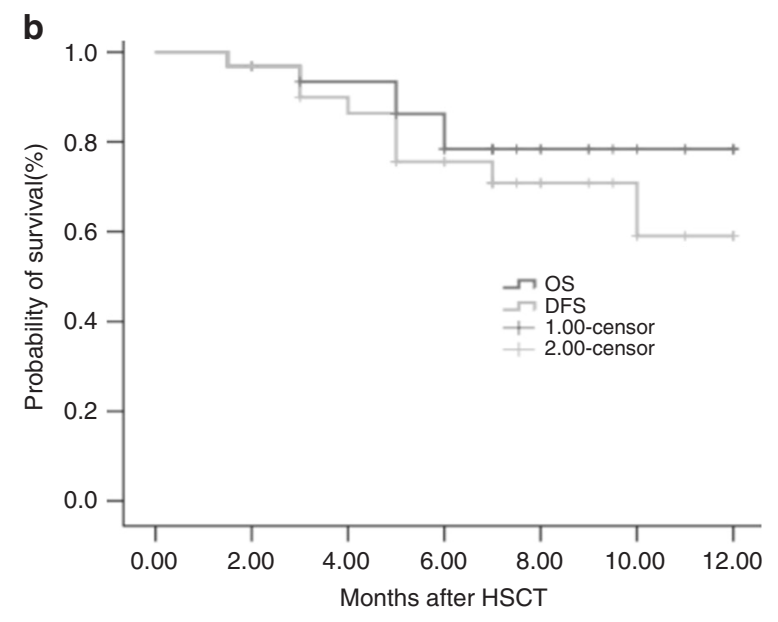

b 
Haplo-HSCT. There was no difference in the median myeloid and platelet engraftment time and the rate of graft failure. We speculated that the addition of low dose of ATG $(5 \mathrm{mg} / \mathrm{kg})$ at pretransfusion would ensure the engraftment. High dose of $\mathrm{CD}_{3} 4^{+}$cells in PBSC graft might be one reason to improve the engraftment rate in our study. In our study, 29/32 cases received MAC regimens, which was another reason for a higher engraftment rate. Solomon et al. $[23,24]$ reported that $100 \%$ of engraftment rate was achieved when MAC was given to patients of Haplo-HSCT with PTCy regimen for GvHD prophylaxis.

Mortality from GvHD and infection accounted for the vast majority of NRM in Haplo-HSCT. In our study, NRM was $9.4 \%$, which was comparable to Haplo-HSCT with PTCy regimen and significantly lower than ATG-based GvHD prophylaxis regimens. No patient died from GvHD and only two patients died from infection. Because of the poor immunologic reconstitution, the rate of susceptibility to infection in Haplo-HSCT is higher than HLA-matched HSCT, especially with ATG-based regimens. Tischer et al. [5] retrospectively compared the incidence of virus infections and outcomes in the context of immune reconstitution between PTCy and ATG-based regimens. The results showed that the incidence of herpes virus infection was markedly lower in the PTCy group (22\%) than in the ATG group $(93 \%)$ and the recovery of $\mathrm{CD} 4^{+} \mathrm{T}$ cells on day +100 was faster in the PTCy group. CMV reactivation was also lower in the PTCy group than in the ATG group (30vs $57 \%$ ), virus infection-related mortality (VIRM) was significantly lower in the PTCy group (1-year VIRM, 0\% PTCy vs 29\% ATG; $p=0.009$ ). Twenty-five percent of the patients in the ATG group but no patient in the PTCy group developed PTLD. In our study, median $\mathrm{CD} 4^{+}$lymphocyte counts were $104 / \mu \mathrm{l}$ on day +100 , which were similar with ATG-based regimens $(102 / \mu \mathrm{l})$ and lower than with PTCy $(206 / \mu \mathrm{l})$ at the same time, but on day $+120, \mathrm{CD} 4+$ lymphocyte counts with $240 / \mu \mathrm{l}$ reached the level on day +100 in the PTCy group and higher than that $(157 / \mu \mathrm{l})$ on +180 days in the ATG-based group [5]. These data might imply that immune recovery was faster in our study than with ATG-based regimens and just a little slower than with PTCy regimen. The CIs of CMV and EBV reactivation by day +180 were $37.5 \%$ (95\% CI, $19.8-55.2 \%)$ and $40.6 \%$ (95\% CI, 22.6-58.6\%), respectively, which were lower than with ATG-based regimens and comparable to the PTCy regimen.

Disease relapse remains a significant cause of treatment failure after allogeneic HSCT, especially for patients with active disease. In the present study, six cases relapsed and three of them died. All the six patients were in active disease. One patient was primary refractory with DNMT3-A mutation. The other five patients had no response to salvage chemotherapy. In previous reports [25, 26], PTCy-based regimens did not impact the relapse of hematologic malignancies after Haplo-HSCT as compared with HLA-matched transplantation and with different preconditioning intensity. In a recent report [27] grade II aGvHD could reduce relapse risk and improve the survival of patients with hematological malignancies with PTCy regimen for prophylaxis of GvHD in Haplo-BMT. In the study, all patients received NMAC regimens and all of the grafts were from bone marrow. But in our study, nearly all patients received MAC regimens and all of the grafts were from PBSC. These differences might lessen the effect of mild aGvHD on disease recurrence. The lower NRM (9.4\%) in this study needs to be carefully interpreted, because of younger age, shorter follow-up and lower HCT score $(0-1)$ of patients. The impact of our novel regimen of GvHD prophylaxis on relapse and NRM with longer follow-up and more samples needs to be further evaluated.

Haploidentical and unrelated cord blood (HID and UCB) are alternative donors for transplant patients without HLAmatched related or unrelated donors. The different combination strategies of haploidentical graft and UCB were successfully used to treat patients with hematological disease. The Spanish's group [28, 29] and University of Chicago from America $[30,31]$ reported that the UCB cells in combination with $\mathrm{CD} 34^{+}$selected PBSCs from a related mismatched donor were transplanted to patients with fast engraftment, low incidences of GvHD, and promising longterm results. Tsai et al. [31] reported that haplo/cord reduced-intensity transplantation followed by durable cord blood engraftment achieved similar outcomes compared with HLA-matched unrelated donor (MUD) in older AML and MDS patients. A group from China [32,33] evaluated another combination strategy of un-manipulated haploidentical stem cells combined with a small dose of umbilical cord blood from a third-party donor (haplo-cord transplant) for hematological malignancies, which was followed by durable haploidentical stem cell engraftment. The results showed that haplo-cord transplant may potentially improve the outcome of HID- and UCB-HSCT alone. To improve the outcomes of haploidentical transplantation, the second combination strategy of un-manipulated haploidentical PBSCs with an UCB (Haplo-PBSCT-Cord) was adopted in our study.

In conclusion, this is a pilot study to establish a low-dose ATG with low-dose PTCy as an effective regimen to prevent GvHD in Haplo-PBSCT with a lower risk of virus reactivation and a higher engraftment rate. But this study still had several limitations, including a lower number of samples, a shorter follow-up, the combination of haplo PBSCs with UCB, etc. A prospective randomized trial without UCB co-infused is required to compare the efficacies of this regimen with ATG-based or PTCy-based regiments in Haplo-PBSCT. 
Acknowledgements This work was supported by National Natural Science Foundation of China (NSFC; 81370601) and Clinical Research Innovation Plan of Shanghai General Hospital. They did not influence how the study was conducted or the approval of the manuscript. We are grateful to all of the patients and the co-investigators for their cooperation in this study.

\section{Compliance with ethical standards}

Conflict of interest The authors declare that they have no conflict of interest.

Ethics and dissemination Results from this investigation will be presented in peer-reviewed international journals. In addition, major findings will be disseminated at national and international conferences. In addition, we will bring out major findings to the general public.

Open Access This article is licensed under a Creative Commons Attribution 4.0 International License, which permits use, sharing, adaptation, distribution and reproduction in any medium or format, as long as you give appropriate credit to the original author(s) and the source, provide a link to the Creative Commons license, and indicate if changes were made. The images or other third party material in this article are included in the article's Creative Commons license, unless indicated otherwise in a credit line to the material. If material is not included in the article's Creative Commons license and your intended use is not permitted by statutory regulation or exceeds the permitted use, you will need to obtain permission directly from the copyright holder. To view a copy of this license, visit http://creativecommons. org/licenses/by/4.0/

\section{References}

1. Luznik L, Jalla S, Engstrom LW, Iannone R, Fuchs EJ. Durable engraftment of major histocompatibility complex-incompatible cells after nonmyeloablative conditioning with fludarabine, lowdose total body irradiation, and posttransplantation cyclophosphamide. Blood. 2001;98:3456-64.

2. Wang Y, Liu DH, Liu KY, Xu LP, Zhang XH, Han W, et al. Long-term follow up of haploidentical hematopoietic stem cell transplantation without in vitro $\mathrm{T}$ cell depletion for the treatment of leukemia: nine years of experience at a single center. Cancer . 2013;119:978-85.

3. Wang Y, Chang YJ, Xu LP, Liu KY, Liu DH, Zhang XH, et al. Who is the best donor for a related HLA haplotype-mismatched transplant? Blood. 2014;124:843-50.

4. Liu Q, Xuan L, Liu H, Huang F, Zhou H, Fan Z, et al. Molecular monitoring and stepwise preemptive therapy for Epstein-Barr virus viremia after allogeneic stem cell transplantation. Am J Hematol. 2013;88:550-5.

5. Tischer J, Engel N, Fritsch S, Prevalsek D, Hubmann M, Schulz $\mathrm{C}$, et al. Virus infection in HLA-haploidentical hematopoietic stem cell transplantation: incidence in the context of immune recovery in two different transplantation settings. Ann Hematol. 2015;94:1677-88.

6. Dominietto A, Tedone E, Soracco M, et al. Epstein-Barr virus reactivation after allogeneic hematopoietic stem cell transplant based on molecular monitoring is predictive of lymphoproliferative disease. Bone Marrow Transplant. 2004;33:S192.

7. Luznik L, O'Donnell PV, Symons HJ, Chen AR, Leffell MS, Zahurak M, et al. HLA-haploidentical bone marrow transplantation for hematologic malignancies using nonmyeloablative conditioning and high-dose, posttransplantation cyclophosphamide. Biol Blood Marrow Transplant. 2008;14:641-50.

8. Ruggeri A, Labopin M, Bacigalupo A, Gülbas Z, Koc Y, Blaise $\mathrm{D}$, et al. Bone marrow versus mobilized peripheral blood stem cells in haploidentical transplants using posttransplantation cyclophosphamide. Cancer . 2018;124:1428-37.

9. Bashey A, Zhang MJ, McCurdy SR, St Martin A, Argall T, Anasetti C, et al. Mobiized peripheral blood stem cells versus unstimulated bone marrow as a graft source for T-cell-replete haploidentical donor transplantation using post-transpalnt cyclophosphamide. J Clin Oncol. 2017;35:3002-9.

10. O’Donnell PV, Luznik L, Jones RJ, Vogelsang GB, Leffell MS, Phelps M, et al. Nonmyeloablative bone marrow transplantation from partially HLA-mismatched related donors using post transplantation cyclophophamide. Biol Blood Marrow Transplant. 2002;8:377-86.

11. Wan LP, Wang C, Liu L. Efficicacy and safety of micafungin as prophylaxis for invasive fungal disease in neutropenic patients with hematologic maliganancies. Int J Pharmacol. 2014;10:231-6.

12. Van Esser JW, Niesters HG, van der Holt B, Meijer E, Osterhaus $\mathrm{AD}$, Gratama JW, et al. Prevention of Epstein-Barr viruslymphoproliferative disease by molecular monitoring and preemptive rituximab in high-risk patients after allogeneic stem cell transplantation. Blood . 2002;99:4364-9.

13. Dierickx D, Tousseyn T, Gheysens O. How I treat posttransplant lymphoproliferative disorders. Blood. 2015;126:2274-83.

14. Martinelli G, Trabetti E, Farabegoli P, Testoni N, Bandini G, Motta MR, et al. Early detection of bone marrow engraftment by amplification of hypervariable DNA regions. Haematologica. 1997;82:156-60.

15. Przepiorka D, Weisdorf D, Martin P, Klingemann HG, Beatty P, Hows J, et al. 1994 consensus conference on acute GVHD grading. Bone Marrow Transplant. 1995;15:825-8.

16. Jagasia MH, Greinix HT, Arora M, Williams KM, Wolff D, Cowen EW, et al. National Institutes of Health Consensus Development Project on criteria for clinical trials in chronic graft-versus-host disease: I. The 2014 Diagnosis and Staging Working Group Report. Biol Blood Marrow Transplant. 2015;21:389-401.e1.

17. Jiang Y, Wan LP, Qin YW, Wang XR, Yan SK, Xie KC, et al. Chimerism status is correlated to acute graft-versus-host disease after allogeneic stem cell transplantation. Int J Hematol. 2014;99:323-8.

18. Qin YW, Jiang Y, Wang XR, Wan LP, Yan SK, Wang C, et al. Comparison of STR-PCR and FISH value for monitoring chimerism after sex-mismatched allogeneic hematopoietic stem cell transplantation. Zhong guo Shi Yan Xue Ye Xue Za Zhi. 2014;17:1016-20.

19. El-Cheikh J, Vazquez A, Crocchiolo R, Furst S, Calmels B, Castagna L, et al. Acute GVHD is a strong predictor of full donor $\mathrm{CD} 3+\mathrm{T}$ cell chimerism after reduced intensity conditioning allogeneic stem cell transplantation. Am J Hematol. 2012;87:1074-8.

20. Cheson BD, Bennett JM, Kopecky KJ, Büchner T, Willman CL, Estey EH, et al. International Working Group for Diagnosis, Standardization of Response Criteria, Treatment Outcomes, and Reporting Standards for Therapeutic Trials in Acute Myeloid Leukemia. Revised recommendations of the International Working Group for Diagnosis, Standardization of Response Criteria, Treatment Outcomes, and Reporting Standards for Therapeutic Trials in Acute Myeloid Leukemia. J Clin Oncol. 2003;21:46429. Erratum in: J Clin Oncol. 2004;22(3):576

21. Mayumi H, Himeno K, Tokuda N, Nomoto K. Drug-induced tolerance to allografts in mice. VII. Optimal protocol and mechanism of cyclophosphamide-induced tolerance in an $\mathrm{H}-2$ haplotype-identical strain combination. Transplant Proc. 1986;18:363-9. 
22. Wang Y, Fu HX, Liu DH, Xu LP1, Zhang XH, Chang YJ, et al. Influence of two different doses of antithymocyte globulin in patients with standard-risk disease following haploidentical transplantation: a randomized trial. Bone Marrow Transplant. 2014;49:426-33.

23. Solomon SR, Sizemore CA, Sanacore M, Zhang X, Brown S, Holland HK, et al. Haploidentical transplantation using $\mathrm{T}$ cell replete peripheral blood stem cells and myeloablative conditioning in patients with high-risk hematologic malignancies who lack conventional donors is well tolerated and produces excellent relapse-free survival: results of a prospective phase II trial. Biol Blood Marrow Transplant. 2012;18:1859-66.

24. Solomon SR, Sizemore CA, Sanacore M, Zhang X, Brown S, Holland HK, et al. Total body irradiation-based myeloablative haploidentical stem cell transplantation is a safe and effective alternative to unrelated donor transplantation in patients without matched sibling donors. Biol Blood Marrow Transplant. 2015;21:1299-307.

25. Anderson BE, McNiff J, Yan J, Doyle H, Mamula M, Shlomchik MJ, et al. Memory CD4 $+\mathrm{T}$ cells do not induce graft-versus-host disease. J Clin Invest. 2003;112:101-8.

26. Zheng H, Matte-Martone C, Li H, Anderson BE, Venketesan S, Sheng Tan H, et al. Effector memory CD4 + T cells mediate graftversus-leukemia without inducing graft-versus-host disease. Blood. 2008;111:2476-84.

27. McCurdy SR, Kanakry CG, Tsai HL, Kasamon YL, Showel MM, Bolaños-Meade J, et al. Grade II acute graft-versus-host disease and higher nucleated cell graft dose improve progression-free survival after HLA-haploidentical transplant with post-transplant cyclophosphamide. Biol Blood Marrow Transplant. 2018;24:34352 .
28. Magro E, Regidor C, Cabrera RSanjuán I, Forès R, Garcia-Marco JA, et al. Early hematopoietic recovery after single unit unrelated cord blood transplantation in adults supported by co-infusion of mobilized stem cells from a third party donor. Haematologica. 2006;91:640-8.

29. Bautista G, Cabrera JR, Regidor C, Forés R, García-Marco JA, Ojeda E, et al. Cord blood transplants supported by co-infusion of mobilized hematopoietic stem cells from a third-party donor. Bone Marrow Transplant. 2009;43:365-73.

30. Liu H, Rich ES, Godley L, Odenike O, Joseph L, Marino S, et al. Reduced-intensity conditioning with combined haploidentical and cord blood transplantation results in rapid engraftment, low GVHD, and durable remissions. Blood. 2011;118:6438-45.

31. Tsai SB, Rhodes J, Liu H, Shore T, Bishop M, Cushing MM, et al. Reduced-intensity allogeneic transplant for acute myeloid leukemia and myelodysplastic syndrome using combined CD34selected haploidentical graft and a single umbilical cord unit compared with matched unrelated donor stem cells in older adults. Biol Blood Marrow Transplant. 2018;24:997-1004.

32. Chen J, Wang RX, Chen F, Sun AN, Qiu HY, Jin ZM, et al. Combination of a haploidentical SCT with an unrelated cord blood unit: a single-arm prospective study. Bone Marrow Transplant. 2014;49:206-11.

33. Ke P, Bao XB, Hu XH, Zhuang J, Wu XJ, Liu YJ, et al. Myeloablative conditioning regimens with combined of haploidentical and cord blood transplantation for myelodysplastic syndrome patients. Bone Marrow Transplant. 2018;53:162-8.

34. Sorror ML, Maris MB, Storb R, Baron F, Sandmaier BM, et al. Hematopoietic cell transplantation (HCT)-specific comorbidity index:a new tool for risk assessment before allogeneic HCT. Blood. 2005;106:2912-9. 